\section{(อ) OPEN ACCESS}

\title{
Rationing, racism and justice: advancing the debate around 'colourblind' COVID-19 ventilator allocation
}

\author{
Harald Schmidt $\odot$, ${ }^{1}$ Dorothy E Roberts, ${ }^{2}$ Nwamaka D Eneanya ${ }^{3}$
}

\begin{abstract}
'Medical Ethics and Health Policy, University of Pennsylvania Perelman School of Medicine, Philadelphia, Pennsylvania, USA ${ }^{2}$ Penn Law, Departments of Africana Studies and Sociology, School of Arts and Sciences, University of Pennsylvani, Philadelphia, Pennsylvania, USA ${ }^{3}$ Renal-Electrolyte and Hypertension Division, Perelman School of Medicine, University of Pennsylvania, Philadelphia, Pennsylvania, USA
\end{abstract}

\section{Correspondence to} Dr Harald Schmidt, Medical Ethics and Health Policy, University of Pennsylvania Perelman School of Medicine, Philadelphia, PA 19104, USA; schmidth@upenn.edu

Received 31 August 2020 Revised 27 October 2020 Accepted 16 November 2020 Published Online First 6 January 2021

\section{SLinked}

- http://dx.doi.org/10.1136/ medethics-2021-107395

- http://dx.doi.org/10.1136/ medethics-2021-107456

- http://dx.doi.org/10.1136/ medethics-2021-107696

Check for updates

(C) Author(s) (or their employer(s)) 2022. Re-use permitted under CC BY-NC. No commercial re-use. See rights and permissions. Published by BMJ.

To cite: Schmidt $\mathrm{H}$, Roberts DE, Eneanya ND. $J$ Med Ethics

2022;48:126-130.

\section{ABSTRACT}

Withholding or withdrawing life-saving ventilators can become necessary when resources are insufficient. In the USA, such rationing has unique social justice dimensions. Structural elements of dominant allocation frameworks simultaneously advantage white communities, and disadvantage Black communities - who already experience a disproportionate burden of COVID-19related job losses, hospitalisations and mortality. Using the example of New Jersey's Crisis Standard of Care policy, we describe how dominant rationing guidance compounds for many Black patients prior unfair structural disadvantage, chiefly due to the way creatinine and life expectancy are typically considered.

We outline six possible policy options towards a more just approach: improving diversity in decision processes, adjusting creatinine scores, replacing creatinine, dropping creatinine, finding alternative measures, adding equity weights and rejecting the dominant model altogether. We also contrast these options with making no changes, which is not a neutral default, but in separate need of justification, despite a prominent claim that it is simply based on 'objective medical knowledge'. In the regrettable absence of fair federal guidance, hospital and state-level policymakers should reflect on which of these, or further options, seem feasible and justifiable. Irrespective of which approach is taken, all guidance should be supplemented with a monitoring and reporting requirement on possible disparate impacts. The hope that we will be able to continue to avoid rationing ventilators must not stand in the way of revising guidance in a way that better promotes health equity and racial justice, both to be prepared, and given the significant expressive value of ventilator guidance.

\section{INTRODUCTION}

Withholding or withdrawing life-saving ventilators can become necessary when resources are insufficient. So far, US hospitals have been able to avoid rationing ventilators. But we are still in the middle of the pandemic. Easing lockdown measures, and future waves, especially when combined, can still make wrenching decisions necessary that clinicians abroad faced during peak impact periods. In the USA, rationing has unique social justice dimensions. Dominant allocation frameworks aim to maximise utility, but insufficiently reflect critical equity concerns. In particular, they disadvantage Black communities-who already experience a disproportionate burden of COVID-19-related job losses, hospitalisations and mortality, ${ }^{1-3}$ against a background of historical and structural disadvantage in healthcare ${ }^{4-6}$ and common disregard for basic health needs. ${ }^{7}$ Given how race and race correction are used in modern medical decision-making, evaluating ventilator rationing protocols is crucial.

\section{BACKGROUND}

Imagine this hypothetical scenario: An intensive care unit (ICU) in a larger metropolitan hospital has 12 ventilators. Eleven are in use. Three critically ill patients with equally severe COVID-19 symptoms qualify for admission. All three have developed respiratory failure requiring use of a ventilator. John is a 55- year-old white accountant. He has comprehensive employer-sponsored health insurance, and is from a well-off suburb, with an average life expectancy of 85 years. $^{8} \mathrm{He}$ is generally healthy but has alcohol dependence. James is a currently unemployed Black sales assistant, also 55 . He has poorly controlled hypertension, mild chronic kidney disease and asthma, and lives in a worse-off neighbourhood where many die some 25 years earlier than in John's neighbourhood. ${ }^{8}$ Martin, a recently furloughed hotel worker, is also Black and 55, and from a neighbourhood with an average life expectancy of 70 years. ${ }^{8} \mathrm{He}$ has severe diabetes and advanced chronic kidney disease.

Treating patients equally should be a central goal of medicine. Three main approaches could be taken to allocate the remaining ventilator. First, a lottery could give everyone a seemingly equal chance. However, there is no baseline equality: James' and Martin's poor health reflects historical and structural disadvantages, ${ }^{45}$ and conversely, historical and structural advantages shaped John's better health. In a just society, poor health would be distributed equally across racial and income groups. Yet, in ours, it is not. Structural factors such as more favourable work, living and housing situations, better access to public health measures and health insurance are reasons the white majority enjoy on average better general health and life expectancy. An unqualified lottery would therefore simultaneously further increase John's past advantage, and reaffirm and compound ${ }^{9}$ James' and Martin's prior disadvantage. Perhaps James and Martin should therefore be given a second option: proportionately higher chances through a weighed lottery. Third is the current dominant model, which, in consequence, has the opposite impact: it simultaneously increases John's chances and decreases James' and Martin's.

\section{COVID-19 TRIAGE IN POLICY AND PRACTICE}

The dominant model abstracts from concrete historical and social contexts. ${ }^{10}$ It relies on the premise that ventilators would be wasted on someone who 
Table 1. Multi-principle Strategy to Allocate Critical Care During a Public Health Emergency

\begin{tabular}{|c|c|c|c|c|c|}
\hline \multirow[t]{2}{*}{ Principle } & \multirow[t]{2}{*}{ Specification } & \multicolumn{4}{|c|}{ Point System* } \\
\hline & & \begin{tabular}{|l|}
1 \\
\end{tabular} & 2 & 3 & 4 \\
\hline Save lives & $\begin{array}{l}\text { Prognosis for } \\
\text { short-term } \\
\text { survival (SOFA } \\
\text { score") }\end{array}$ & $\begin{array}{l}\text { SOFA score } \\
<6\end{array}$ & $\begin{array}{l}\text { SOFA score } \\
6-8\end{array}$ & $\begin{array}{l}\text { SOFA score } \\
9-11\end{array}$ & $\begin{array}{l}\text { SOFA score } \\
\geq 12\end{array}$ \\
\hline $\begin{array}{l}\text { Save life- } \\
\text { years }\end{array}$ & $\begin{array}{l}\text { Prognosis for } \\
\text { longer-term } \\
\text { survival (medical } \\
\text { assessment of } \\
\text { prospects for } \\
\text { survival after } \\
\text { hospital } \\
\text { discharge) }\end{array}$ & $\ldots$ & $\begin{array}{l}\text { Life } \\
\text { expectancy < } \\
5 \text { years } \\
\text { despite } \\
\text { successful } \\
\text { treatment of } \\
\text { acute } \\
\text { condition } \\
\end{array}$ & $\ldots$ & $\begin{array}{l}\text { Death likely } \\
\text { within } 1 \text { year } \\
\text { despite } \\
\text { successful } \\
\text { treatment of } \\
\text { acute } \\
\text { condition }\end{array}$ \\
\hline
\end{tabular}

should similarly be divided into 4 ranges.

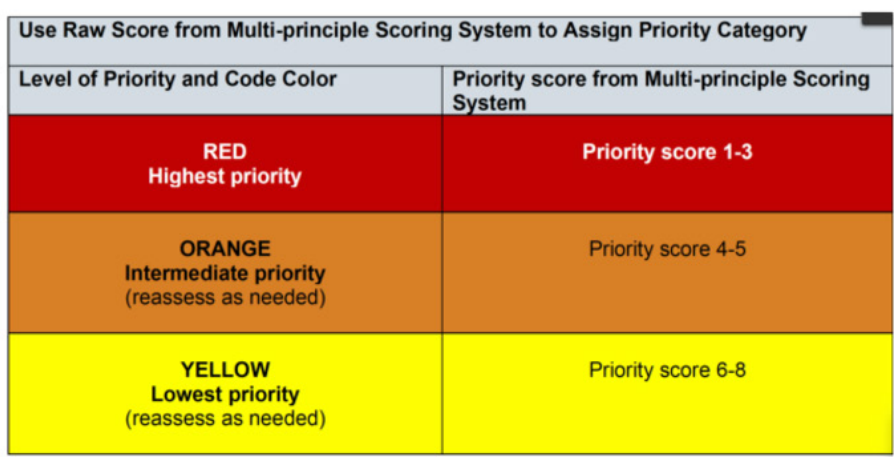

Figure 1 New Jersey policy on prioritising ventilator access by integrating SOFA and life expectancy scores in a point system. ${ }^{13}$

might die while being ventilated, or might die soon after leaving the hospital. Instead, to save the most lives, and life years, those who are most likely to survive treatment, and to live sufficiently long afterwards, should be selected-whoever this may be.

The dominant model can be justified by different versions of consequentialism, or by so-called multicriteria approaches that combine several values and principles. ${ }^{11}{ }^{12}$ For example, like other states, New Jersey (NJ) adopted a multicriteria framework in a Gubernatorial Directive with a goal to do 'the greatest good for the greatest number'. ${ }^{13}$ Using NJ's Directive as a concrete example, we illustrate how such approaches compound disadvantage for Black patients. Naturally, there are direct implications for states or hospitals with identical or similar approaches.

NJ's Directive aims to guide practitioners, provide transparency and bar the states' agencies from bringing criminal prosecutions against healthcare facilities adopting the rationing guidance. Ventilator access is determined by assigning each patient a numerically ranked score, 'based on objective medical knowledge'. 13

A central and widely used ${ }^{1415}$ tool is the Sequential Organ Failure Assessment (SOFA) ${ }^{16}$ that assesses eight separate measures to compute an overall score for predicting the likelihood of death in the ICU. The higher the score, the more likely a patient's death. NJ's Directive combines the SOFA score with another score assessing near-term survival to produce an overall raw score. This raw score is then used to assign patients to priority groups (see figure 1).

To determine how well kidneys work, SOFA incorporates creatinine, a waste product of muscles, found in blood. The main problem with creatinine is that it is myopic to view it as an objective measure of kidney function alone: it simultaneously measures social disadvantages that may cause higher creatinine. (The same point applies to considering existing comorbidities in ways that reduce chances of receiving a ventilator, as five of the published state frameworks do. ${ }^{15}$ )

Some literature has suggested uniform differences in creatinine levels by race, and historically higher average creatinine levels in Black people have been attributed to higher muscle mass. ${ }^{17}$ However, there is weak scientific evidence for this hypothesis, and increasing awareness that measuring differences across races is severely complicated by the fact that race is a social construct. ${ }^{18} 19$ Further, a biological trait cannot be mapped categorically onto a group of people that is both socially defined and composed of widely differing physiological profiles that reflect different circumstances of living far more than genetics. ${ }^{2021}$ For example, limited evidence suggests that genetic factors substantially increase the risk of end-stage kidney disease in $13 \%$ of
African Americans, ${ }^{22}$ but even then, by implication, the vast majority of the higher prevalence of the disease is non-genetic, and due to different living circumstances that are more common for the respective group. ${ }^{6}$ Relatedly, creatinine is higher in Black communities because of higher rates of chronic kidney disease, due to higher rates of diabetes and high blood pressure, ${ }^{23} 24$ that are best understood as the consequences of health inequities and structural racism. ${ }^{4-6}$

Creatinine becomes relevant for social justice due to the way SOFA functions and is integrated into NJ's Point System. SOFA measures creatinine in five tiers. The first assigns 0 point to patients with levels $<1.2 \mathrm{mg} / \mathrm{dL}$. This does not negatively affect patients' chances of receiving a ventilator (figure 1). However, 1 point is assigned for levels $1.2-1.9$, and up to 4 for levels $\geq 5$. A single added point can make the difference between getting, and not getting, a ventilator.

Let's return to John, James and Martin. Assume that John has a creatinine level of 1.18 (within the normal range). ${ }^{25}$ On SOFA, he receives no points for creatinine, but for acute respiratory impairment and his other health conditions, including a higher bilirubin score due to liver disease from his alcohol dependence: his overall SOFA score is $6 .^{26}$ There is not a disproportionately higher incidence of alcohol-related liver disease among white people: the risk of a higher score due to bilirubin is equal for all three individuals. ${ }^{27}$ Since John is estimated to live more than 5 years on discharge, his total raw score is 1 , with assignment to the high priority group.

James' SOFA score is largely identical to John's. He, too, has acute respiratory impairment and, in addition, receives an extra creatinine point due to his mild chronic kidney disease (level=1.4), ${ }^{25}$ His total SOFA score is 7 , translating into 2 points on the Point System. His advanced diabetes and poorly controlled hypertension (reasons that many in his neighbourhood die decades before those in other neighbourhoods) result in his remaining posthospital survival being estimated at less than 5 years. He receives 2 additional points, an overall raw score of 4 , and intermediate priority classification.

Martin's creatinine is the highest at 4.1 , scoring 4 on SOFA. Like John and James, his acute respiratory impairment registers on the SOFA subscore, as do his other health conditions that again reflect prior structural disadvantage and are scored at 8 ; his total SOFA score is 12 . While his health is poor, he is not estimated to die within 5 years because his wife has been medically cleared to pre-emptively donate a kidney to him. But the Point System assigns him to the intermediate priority group. 
NJ's scoring algorithm therefore means that John will receive the ventilator, while James and Martin will be 'reassess[ed] as needed'. ${ }^{13}$

\section{THE WAY FORWARD}

When asked to explain the disproportionate impact of COVID-19 on Black communities (with, on average, twice and up to sixfold higher mortality rates compared with whites ${ }^{3}$ ), Secretary of Health Alex Azar recently posited 'higher risk profiles'

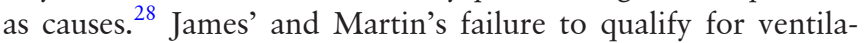
tors might likewise be explained by reference to risk factors, captured numerically through value-neutral objective measures. But justice in healthcare, and establishing fair rationing protocols, require a focus on the causes, and on the causes of the causes, of poor health. ${ }^{29-31}$

Higher creatinine levels are not distributed equally across the population, but are clustered in ways that stem from structural inequalities. Despite appearing objective, SOFA's conceptualisation of creatinine in interaction with guidance such as NJ's Directive gives Black people a lesser chance at receiving a ventilator, compounding prior injustice and embedding structural racism, even if unintended.

So how should decision makers proceed? We consider seven possible options arranged from the least to the most comprehensive type of changes: improving diversity in decision processes, adjusting creatinine scores, replacing creatinine, dropping creatinine, finding alternative measures, adding equity weights and rejecting the SOFA (and point score) model. We focus on SOFA, as the best available data suggest that it is the most widely used assessment tool (of 26 states with publicly available ventilator guidelines, 15 recommend using SOFA). ${ }^{15}$ In many ways, the discussion equally applies to other assessment tools (such as modified SOFA, ASA) but in the interest of clarity we centre the discussion on the dominant model.

\section{Processes: improving diversity}

One helpful suggestion is to require 'triage officers and appealscommittee members to have some expertise in equity, and to come from diverse backgrounds. ${ }^{2}$ Such steps are necessary since SOFA unfairly advantages white patients, and disadvantages, particularly, Black patients. Potentially, these measures could help with valuing lives more equally and reducing probable implicit bias, ${ }^{32}$ particularly when assessing remaining life expectancy. For example, 40-year-old men with chronic kidney disease live between 9 and 30 more years. ${ }^{33}$ To some clinicians, James' likely death within 5 years may be self-evident, and justify assigning two extra points. But others, more familiar with his situation and looking at options through a health equity lens, ${ }^{103435}$ might be more sceptical.

Still, when it comes to creatinine, equity training or diverse backgrounds seem unlikely to counter its impact, which, when challenged, will likely be justified as unassailable 'objective medical knowledge'. ${ }^{13}$ Improving diversity in processes might therefore improve chances for James (who might not receive points for reduced life expectancy), but not for Martin (whose higher creatinine levels will deprive him of the high priority group, regardless).

\section{Adjusting creatinine}

A more direct way of eliminating SOFA's built-in bias against Black patients could be to adjust creatinine penalties by race. Instead of a 'colourblind' single creatinine threshold, NJ's Directive could account for the fact that the noted structural factors-particularly higher levels of advanced chronic kidney disease $^{36}$-imply higher chances of increased creatinine levels in Black populations. The SOFA point threshold could be adjusted by tying the 1 point penalty not to a single creatinine threshold, but to average levels, differing for races. This could avoid unfairly advantaging John, would instantly level the playing field for James and at least improve Martin's chances.

The absence of creatinine race correction in ventilator rationing is noteworthy: creatinine is routinely adjusted by race in calculators used to determine medical care, ${ }^{21}$ including for rationing kidney transplants. ${ }^{37}$ Only, there, race correction has the opposite effect: adjusting creatinine can make Black patients ineligible for treatment, ${ }^{17}$ and can delay kidney transplant evaluation referrals. ${ }^{38}$ The opportunity to avoid reducing Black patients' ventilator chances by adopting the routinely used race correction was nevertheless passed up.

While adjusting scores in this way could immediately improve James' and Martin's chances, the main, and important, downside is that it could be viewed as supporting harmful race corrections that rely on assumptions of race-based biological differences, and thus promote the false view of race as a biological rather than social category.

\section{Dropping creatinine}

Perhaps the simplest option would be to eliminate creatinine from SOFA. John's unfair advantage would be eliminated along with James' and Martin's unfair disadvantage: all three would be equals.

The principal challenge to this proposal is the power of path dependency. Clinicians routinely use kidney function (in addition to pulmonary, cardiac and liver functions) as an important measure of overall health. Clinicians and administrators would be extremely reluctant to risk compromising SOFA's overall validation and lose an integral measure in an approach that is widely used. $^{14} 15$

\section{Alternative measures}

An alternative might be to replace creatinine with biomarkers estimating kidney function without variations across races. Studies have demonstrated that cystatin $C$ is promising in this regard. ${ }^{39} 40$ Still, John's unfair advantage would continue, along with James' and Martin's unfair disadvantages, due to the disproportionate prevalence of kidney disease among the two racial groups. ${ }^{36}$ In addition, for the present context, cystatin $\mathrm{C}$ has not been validated as part of SOFA.

\section{Adding equity weights}

A more pragmatic approach would seek not to interfere with the basics or internal mechanics of currently established evaluation frameworks, but to add feasible corrective measures that can mitigate disparate impact. ${ }^{41} 42$

Here, John, James and Martin could all be evaluated via SOFA and a point system such as NJ's. However, a social disadvantage score could then be added, such that James' and Martin's scores improve in ways that offset, at least, their creatinine penalties.

The above-cited data on the correlation of zip code, life expectancy and COVID-19-related impact are irrefutable. Area deprivation index (ADI) data ${ }^{43}$ capture them in ways that can be integrated easily.

The ADI has already been used for targeting health services. ${ }^{43}$ Developing and amplifying prior proposals, ${ }^{44}$ a recent report by the National Academy of Sciences, Engineering, and Medicine set out a similar approach for equitable vaccine allocation. ${ }^{46}$ Adjusting by disadvantage would also build on precedent of 
rationing in other areas with major social justice implications, such as school access. So-called reserve systems have been used to ensure that 'colourblind' assessments (focusing exclusively on 'objective' entry examination results) no longer disproportionately privilege the better-off, but also provide allocations for worse-off populations, with recent adaptations for ventilator rationing. ${ }^{47}$ Equity weights can instantly eliminate John's unfair advantage, and James' and Martin's unfair disadvantage. While practically straightforward, the strongest challenge is a legal one. ${ }^{48}$ However, given that a major part of what explains the consequences of structural racism has to do with unjust law, and given that, by implication, it is current law that confers more benefits to the white majority who were already more privileged to start with, there is likely no better time for revisiting the underlying legal justification than now.

\section{Dropping SOFA}

The most radical approach would be dropping SOFA altogether. The American College of Chest Physicians noted considerable concern about SOFA in its recent COVID-19 guide: 'a growing body of evidence suggests such scoring systems are unlikely to predict critical care outcomes with sufficient accuracy,... or be for a useful basis for triage decisions based upon the current protocol cut points' ${ }^{49}$ Disability rights groups have identified further problems, for example, that SOFA penalises pre-existing speech disability due to its reliance on the Glasgow Coma Scale, noting also that states like California (with an approach very similar to NJ's) failed to sufficiently solicit public comments on its triage rules. ${ }^{50}$

Yet, for James and Martin, the implications of abandoning SOFA (or similar creatinine-integrating measures, such as LAPS2 (Laboratory Acute Physiology Score)) are not obvious. Martin might be assigned to the high priority group. But post-treatment survival could loom even larger, and James might continue to be disadvantaged.

Ultimately, the question of the role of SOFA and point systems is about the extent to which such approaches should be sensitive to, or ignore, social justice implications. The dominant approach appeals to many clinicians as its seemingly objective numeric records can be verified in the same way by different laboratories, be recorded easily in charts and be used to track patients' progress. Yet, it is not neutral-but has baked into it factors that advantage John. The most radical approach would flip the assessment, and in allocating scarce resources would not give priority to those who already had more previously. Instead, the protocol could have preference for those who received the least, without fraught assessments of posthospital survival, and focus only on avoiding allocating treatment to those certain to die during its course.

\section{CONCLUSION}

A final option is simply to leave things as they are. One might agree that it is tragic that COVID-19-associated morbidity and mortality directly mirrors more general morbidity and mortality inequities across races and zip codes-but nonetheless argue that a pandemic is the wrong time to implement what seems like affirmative action for ventilators. Moreover, opening the discussion now could risk regressing to oftentimes worse approaches, such as first come, first served.

We disagree. First, it is wrong to view as neutral that John has higher chances for a ventilator under the current allegedly objective 'colourblind' SOFA/point score system, and to ignore that it compounds James' and Martin's lower prior unfair disadvantage. ${ }^{9}$ Second, failing to implement any measure that can mitigate the effect that creatinine scores reduce Black people's fair chances for ventilators will only exacerbate the dramatic impact COVID-19 has on disadvantaged populations, possibly contributing to lasting social trauma and injustice. ${ }^{41}$

We have offered above six potential ways to respond, each with discrete advantages and disadvantages. In the regrettable absence of fair federal guidance, hospital and state-level policymakers should reflect on which of these, or further options, seem feasible and justifiable. In any case, all guidance should be supplemented with a monitoring and reporting requirement on possible disparate impacts of the ultimately adopted policy. Specifically, there needs to be clear accounting on whether there are differences across racial and income groups in terms of who receives ventilators, and who is removed from them. ${ }^{5152}$

Further, the dominant approach itself should be subject to broader public evaluation. It is unclear on what grounds prioritising prognosis via SOFA and life expectancy (even if limited to 5 years) expresses valuing all lives equally. Qualitative research (cited as having informed the $\mathrm{NJ}$ guidance ${ }^{3}$ ) illustrates this. Researchers elicited, separately, views of participants from an affluent suburb (Howard County), and from a worse-off innercity neighbourhood (East Baltimore). Eighty-three per cent of suburban respondents thought 'priority to those most likely to survive' would be an acceptable principle, $83 \%$ (finding it by far the most acceptable of six principles), compared with only $33 \%$ from the inner city. ${ }^{53}$ Ventilator rationing guidance such as NJ's therefore needs to be informed more fully by a more diverse range of voices.

Hopefully, we will be able to continue to avoid rationing ventilators. But such hope must not stand in the way of revising guidance in a way that better promotes health equity and racial justice, both to be prepared, and given the significant expressive value of ventilator guidance.

Correction notice This paper has been updated since first published to revise Reference 48 and to include provenance and peer review statement.

Acknowledgements We are grateful to the reviewer for helpful comments that enabled us to clarify key issues; to Sonia Sethi for background research and discussion of central points; to Gary Weissman for comments on an earlier version of the manuscript; and to Peter Reese for illuminating central questions. As always, all possible remaining errors are the authors' alone.

Contributors HS wrote the first draft. All authors subsequently reviewed, revised and edited the manuscript with equal input and a particular emphasis on issues within their respective areas of expertise.

Funding The authors have not declared a specific grant for this research from any funding agency in the public, commercial or not-for-profit sectors.

Competing interests None declared.

Patient consent for publication Not required.

Provenance and peer review Not commissioned; externally peer reviewed.

Data availability statement All data relevant to the study are included in the article.

Open access This is an open access article distributed in accordance with the Creative Commons Attribution Non Commercial (CC BY-NC 4.0) license, which permits others to distribute, remix, adapt, build upon this work non-commercially, and license their derivative works on different terms, provided the original work is properly cited, appropriate credit is given, any changes made indicated, and the use is non-commercial. See: http://creativecommons.org/licenses/by-nc/4.0/.

\section{ORCID iD}

Harald Schmidt http://orcid.org/0000-0003-4806-8816

\section{REFERENCES}

1 Wadhera RK, Wadhera P, Gaba P, et al. Variation in COVID-19 hospitalizations and deaths across New York City boroughs. JAMA 2020;323(21). 
2 Cleveland Manchanda E, Couillard C, Sivashanker K. Inequity in crisis standards of care. N Eng/ J Med 2020;383(4):e16.

3 APM Research Lab. The color of coronavirus: covid-19 deaths by race and ethnicity in the U.S, 2020. Available: https://www.apmresearchlab.org/covid/deaths-by-race [Accessed 1 Jul 2020].

4 Dwyer-Lindgren L, Bertozzi-Villa A, Stubbs RW, et al. Inequalities in life expectancy among US counties, 1980 to 2014: temporal trends and key drivers. JAMA Intern Med 2017;177(7):1003-11.

5 Berwick DM. The moral determinants of health. JAMA 2020;324(3).

6 Forde AT, Sims M, Muntner P, et al. Discrimination and hypertension risk among African Americans in the Jackson heart study. Hypertension 2020;76(3):715-23.

7 Law AC, Weissman GE, Iwashyna TJ. A dangerous myth: does speaking imply breathing? Ann Intern Med 2020;173(9):754-5.

8 See, for example, data for Chicago, Newark, New York, Philadelphia. Available: https:// www.cityhealthdashboard.com [Accessed 1 Jul 2020].

9 Hellman D. Indirect Discrimination and the Duty to Avoid Compounding Injustice Virginia Public Law and Legal Theory Research Paper No 2017;2017-53 2017.

10 Chomilo N, Heard-Garris N, DeSilva M, et al. The harm of a Colorblind allocation of scarce resources. In. Healt Affiars Blog 2020.

11 Emanuel EJ, Persad G, Upshur R, et al. Fair allocation of scarce medical resources in the time of Covid-19. New England Journal of Medicine 2020;382(21):2049-55.

12 White $D B$, Lo B. A framework for rationing ventilators and critical care beds during the COVID-19 pandemic. JAMA 2020;323(18):1773-4

13 Grewal GS. Directive Regarding Non-Prosecution of Healthcare Facilities and Professionals Adhering to Triage Protocols During COVID-19 Pandemic - Attorney General Law Enforcement Directive No. 2020-03. In: State of new Jersey, office of the attorney General. Trenton, NJ: Department of Law and Public Safety, 2020.

14 Matheny Antommaria AH, Gibb TS, McGuire AL, et al. Ventilator triage policies during the COVID-19 pandemic at U.S. hospitals associated with members of the association of bioethics program directors.. Annals of Internal Medicine 2020.

15 Piscitello GM, Kapania EM, Miller WD, et al. Variation in ventilator allocation guidelines by US state during the coronavirus disease 2019 pandemic: a systematic review. JAMA Netw Open 2020;3(6).

16 Vincent JL, Moreno R, Takala J, et al. The SOFA (sepsis-related organ failure assessment) score to describe organ dysfunction/failure. on behalf of the Working group on sepsis-related problems of the European Society of intensive care medicine. Intensive Care Med 1996;22(7):707-10.

17 Grubbs V. Precision in GFR reporting: let's stop playing the race card. Clin J Am Soc Nephrol 2020;15(8).

18 Omi M, Winant H. Racial formation in the United States. Routledge, 2014.

19 Roberts D. Fatal invention: how science, politics, and big business re-create race in the twenty-first century. New Press/ORIM, 2011.

20 Yudell M, Roberts D, DeSalle R, et al. Taking race out of human genetics. Science 2016;351(6273):564-5.

21 Morris $\mathrm{H}$, Mohan $\mathrm{S}$. Using race in the estimation of glomerular filtration rates: time for a reversal? Curr Opin Nephrol Hypertens 2020;29(2):227-31.

22 Dummer PD, Limou S, Rosenberg AZ, et al. APOL1 kidney disease risk variants: an evolving landscape. Semin Nephrol 2015;35(3):222-36.

23 Grubbs V, Levey AS, Titan SM, Powe NR. Precision in GFR reporting: let's stop playing the race card. Clin J Am Soc Nephrol 2020;15(8).

24 Cobb RJ, Thorpe RJ, Norris KC. Everyday discrimination and kidney function among older adults: evidence from the health and retirement study. J Gerontol A Bio/ Sci Med Sci 2020:75(3):517-21.

25 BMJ Best Practice. Assessment of elevated creatinine 2020.

26 Note that while the examples of John, James and Martin are constructed, the used SOFA levels closely track currently available Covid-19 data. Three large studies indicate that patients have low overall scores of 6-7 see "Triage of Critical Care Resources During COVID-19" Webinar by the American College of Chest Physicians, April 16, 2020, and Maves RC, Downar J, Dichter JR, et al. Triage of Scarce Critical Care Resources in COVID-19 An Implementation Guide for Regional Allocation: An Expert Panel Report of the Task Force for Mass Critical Care and the American College of Chest Physicians. CHEST 2020;158(1):212-25 http://www.chestnet.org/ Guidelines-and-Resources/COVID-19/Advice-From-the-Front-Lines\#Racism

27 Rich NE, Oji S, Mufti AR, et al. Racial and ethnic disparities in nonalcoholic fatty liver disease prevalence, severity, and outcomes in the United States: a systematic review and meta-analysis. Clin Gastroenterol Hepatol 2018;16(2):198-210.
28 Law T. HHS Secretary Azar Says America's Disproportionate COVID-19 Death Toll Is Due to Communities With 'Greater Risk Profiles'. Time Magazine 2020.

29 Link BG, Phelan J. Social conditions as fundamental causes of disease. J Health Soc Behav 1995;Spec No:80-94.

30 Marmot M. Universal health coverage and social determinants of health. Lancet 2013;382(9900):1227-8

31 Taylor R, Rieger A. Medicine as social science: Rudolf Virchow on the typhus epidemic in upper Silesia. Int J Health Serv 1985;15(4):547-59.

32 Pearson AR, Dovidio JF, Gaertner SL. The nature of contemporary prejudice: insights from aversive racism. Soc Personal Psychol Compass 2009;3(3):314-38.

33 National Kidney Foundation. Dialysis, 2015. Available: https://www.kidney.org/atoz/ content/dialysisinfo [Accessed 1 Jul 2020].

34 Government Alliance on Race and Equity, (GARE). Racial equity tool, 2020. Available: https://www.racialequityalliance.org/tools-resources/ [Accessed 1 Jul 2020].

35 Seattle Race and Social Justice Initiative, (RSJI). Racial equity toolkit, 2020. Available: https://www.seattle.gov/rsji/about [Accessed 1 Jul 2020].

36 United States Renal Data System, (USRDS). Us renal data system 2019 annual data report: epidemiology of kidney disease in the United States. American Journal of Kidney Disease 2019

37 Eneanya ND, Yang W, Reese PP. Reconsidering the consequences of using race to estimate kidney function. JAMA 2019;322(2):113-4.

38 Vyas DA, Eisenstein LG, Jones DS. Hidden in plain sight — reconsidering the use of race correction in clinical algorithms. New England Journal of Medicine 2020;383(9):874-82

39 Delanaye P, Cavalier E, Morel J, et al. Detection of decreased glomerular filtration rate in intensive care units: serum cystatin $C$ versus serum creatinine. BMC Nephrol 2014;15:9.

40 Stevens LA, Coresh J, Schmid CH, et al. Estimating GFR using serum cystatin C alone and in combination with serum creatinine: a pooled analysis of 3,418 individuals with CKD. Am J Kidney Dis 2008:51(3):395-406.

41 Schmidt H. The Way We Ration Ventilators Is Biased - Not every patient has a fair chance. New York Times 2020.

42 Sederstrom N. The "Give Back": Is There Room For It?. In. BIOETHICS.NET 2020.

43 Neighborhood Atlas. University of Wisconsin school of medicine and public health DOM, 2020. Available: https://www.neighborhoodatlas.medicine.wisc.edu/ [Accessed 1 Jul 2020].

44 Schmidt H. Vaccine rationing and the urgency of social justice in the Covid-19 response. Hastings Cent Rep 2020;50(3):46-9.

45 Fair allocation of vaccines, ventilators and antiviral treatments: leaving no ethical value behind in health care rationing. arXiv 2020.

46 Gayle HFW, Brown L, Kahn B. A framework for equitable allocation of vaccine for the novel coronavirus 2020

47 Pathak PA, Sönmez T, Unver MMU. Leaving no ethical value behind: triage protocol design for pandemic rationing, working paper No. 26951, 2020. National Burerau of economic research. Available: https://www.nber.org/papers/w26951

48 Persad G. Allocating medicine fairly in an unfair pandemic (September 25, 2020). University of Illinois law review, 2020. Forthcoming, U Denver legal studies research paper No. 20-26. Available: SSRN: https://ssrn.com/abstract=3699769

49 Maves RC, Downar J, Dichter JR, et al. Triage of scarce critical care resources in COVID-19 an implementation guide for regional allocation: an expert panel report of the task force for mass critical care and the American College of chest physicians. Chest 2020;158(1):212-25.

50 Disability Rights Education \& Defense Fund. Letter From DREDF and Additional Organizations Opposing California's Health Care Rationing Guidelines, 2020. Available: https://dredf.org/letter-opposig-californias-health-care-rationing-guidelines/ [Accessed 1 Jul 2020].

51 Peterson A, Largent EA, Karlawish J. Ethics of reallocating ventilators in the covid-19 pandemic. BMJ 2020;369:m1828.

52 Liddell K, Skopek JM, Palmer S, et al. Who gets the ventilator? important legal rights in a pandemic. J Med Ethics 2020;46(7):421-6.

53 Daugherty Biddison EL, Gwon H, Schoch-Spana M, et al. The community speaks: understanding ethical values in allocation of scarce lifesaving resources during disasters. Ann Am Thorac Soc 2014;11(5):777-83. 